\title{
Fatigue strength of inner knurled interference fit joined by forming and cutting methods
}

\author{
L. Suchý \\ Chemnitz University of Technology, Institute of Design Engineering and Drive Technology, Germany \\ Reichenbainer Straße 70, 09126 Chemnitz, Germany \\ lukas.suchy@mb.tu-chemnitz.de \\ E. Leidich, A. Hasse \\ Chemnitz University of Technology, Institute of Design Engineering and Drive Technology, Germany \\ erbard.leidich@mb.tu-chemnitz.de, alexander.basse@mb.tu-chemnitz.de
}

T. Gerstmann, B. Awiszus

Chemnitz University of Technology, Institute for Machine Tools and Production Processes, Germany

thoralf.gerstmann@mb.tu-chemnitr.de,birgit.awiszus@mb.tu-chemnitz.de

\begin{abstract}
The joining of machine parts by plastic forming is a common method for transmitting forces and torque. In drive trains, the 'knurled interference fit' has a high transmission capacity through the combination of frictional connection and form fit. In the present study, the shaft specimen made of C45 steel is joined with an inner knurled hub made of $16 \mathrm{MnCr} 5$ casehardened steel. The influence of the joining process parameters on the torsional fatigue strength of the shaft-hub connection is experimentally investigated in this paper. The most important parameter is the chamfer angle of the knurled hub, which determines the rate of strain hardening in the material and differs between the cutting and forming joining processes. This study shows that knurled interference fit connections, joined by forming, achieve a higher fatigue strength and a higher maximum static torque than connections joined by cutting.
\end{abstract}

KEYWORDS. Inversed knurled interference fit; Notch fatigue; Joining by plastic forming; High-cycle fatigue testing; Torque transmission.

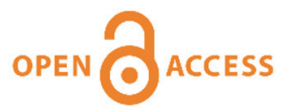

Citation: Suchý, L., Leidich, E., Hasse, A., Gerstmann, T., Awiszus, B., Fatigue strength of inner knurled interference fit joined by forming and cutting methods, Frattura ed Integrità Strutturale, 49 (2019) 429-434.

Received: 30.11 .2019 Accepted: 17.06 .2019 Published: 01.07.2019

Copyright: (C) 2019 This is an open access article under the terms of the CC-BY 4.0, which permits unrestricted use, distribution, and reproduction in any medium, provided the original author and source are credited.

\section{INTRODUCTION}

knurled interference fit (KIF) is a component connection that can be used in various applications, such as torque transmission connections. It combines the friction fit and form fit and creates a permanent part connection with a high power density of transmittable drive torques and axial forces. The connection of the components is established 
through the axial joining of a harder knurled component into a softer undersized component. While joining, a counter profile is incised by performing a plastic deformation on the surface of the softer component.

For decades, the principle of self-forming connections has already been used for joining parts in fine mechanics [1]. Thomas [2] investigated a similar component connection back in the late 60s. He estimated the fundamental joining of torque characteristics of the so-called "press fit with discontinuous groove" [2]. Not until 8 years ago, various approaches have been proposed to describe the static and cyclic torque and bending load capacity of the KIF. Bader reported the minimal hardness ratio of 1.8 [3] and developed empirical calculations for several material combinations. Further calculations of the static load capacity in studies reviewed by the authors are predicated on the shear failure or equivalent stress of the counter profile [3-6]. Some of these studies regard the strain hardening in relation to the shaft chamfer angle $\varphi$, which divides the joining process into cutting and forming joining [7]. Similar to chip removing processes, a sharp edge $\left(\varphi=90^{\circ}\right.$, Figure 1b) of the harder knurled machine part cuts a groove into the softer part, forming a chip. In contrast, a chamfered edge $\left(\varphi<60^{\circ}\right)$ generates a smooth radial forming process, which leads to a massive local plastic strain and an additional elastic radial pressure due to the Young's-modulus-related spring-back effect. Depending on the contact pressure, axial loads can also be transmitted due to friction between the components. Concerning the high-cycle fatigue, the calculation approach in [5] is based on the local stress gradient according to the guideline Analytical Strength Assessment (FKM-Guideline) [8] in combination with the criterion of maximum shear strain. In [9], the authors of the industrial application of KIF in differential gear emphasize the high power density of the connection with simultaneous cost efficiency.

In contrast to the introductory literature, the tool part in the present study is a harder hub with an inner-knurled bore hole (Fig. 1). The counter-profile formation is carried out on the shaft surface. Subsequently, the softer shaft component of the inversed knurled interference fit (I-KIF) is subjected to a more advantageous pressure stress state in contrast to the tensile stress portion of the softer component of the KIF (radial hub expansion). Only the authors in [10] investigated the load capacity and assembling characteristics of I-KIF.

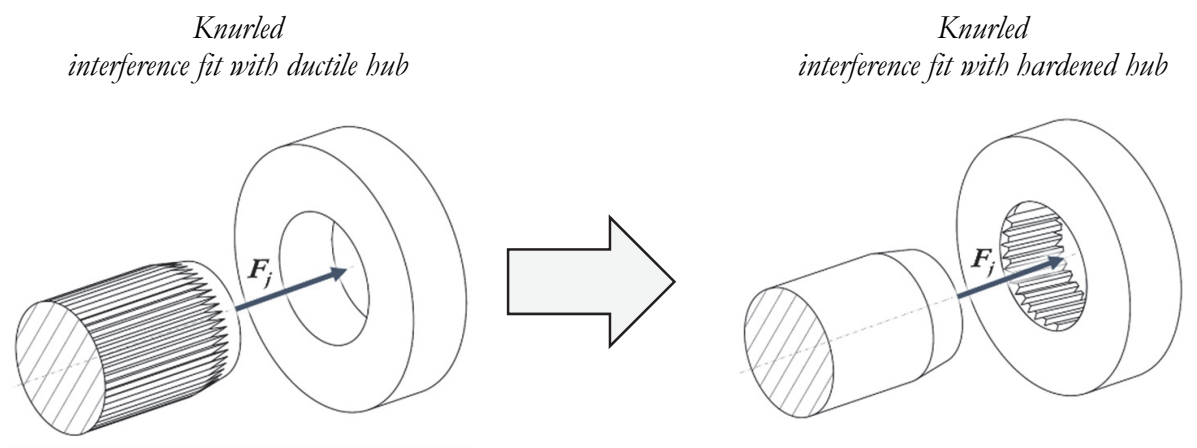

Figure 1: Geometry and material reversion of knurled interference fit

Nevertheless, determining the fatigue strength of the KIF is challenging and has not yet been fully explored.

In the present study, the high-cycle fatigue life of an inversed knurled interference fit (I-KIF) is investigated by means of experimental torque fatigue tests. Regarding the forming and cutting joining process, existing studies on fatigue strength of pre-strained specimen $[11,12]$ suggest a higher fatigue strength of the investigated materials.

\section{EXPERIMENTAL SETUP}

he aim of the experimental investigations is to estimate the fatigue limit of the I-KIF with steel-steel pairing, distinguishing between the two different joining processes.

\section{Specimen specification and testing procedure}

Figure $1 \mathrm{a}-\mathrm{d}$ shows the geometry of the investigated hub specimen made of $16 \mathrm{MnCr} 5$ case-hardened steel. Due to the pulsing axial forming procedure, the knurling is created prior to the heat treatment as described in [6]. The hardness of the shaft specimen made of $\mathrm{C} 45$ untreated steel was $233 \mathrm{HV}$. The connection interference is adjusted by the shaft diameter $D_{o s}$. The slightly oversized shaft shoulder (Figure 1c) defines the supporting length of the connection by the parameter $L_{j}$. Table 1 
summarizes all parameters used in the present study. Table 2 lists the material properties of the investigated specimens. According to [13] and [14], cyclic properties for torsion were determined by a standardized tensile test at room temperature Figure 1d illustrates the assembled I-KIF connection. The joining of the shaft and hub was performed at a joining velocity of $v_{j}=0.5 \mathrm{~mm} / \mathrm{s}$. The coaxiality of the parts was guaranteed by the use of a tight tolerated guiding appliance during the joining process. Additionally, the diameter of the end shaft section was adjusted for guiding purposes.

Similar to the conventional KIF, the type of joining process was determined by the chamfer angle of the harder joining part. In [10], different hub chamfer angles in ranges of $\varphi=5^{\circ}$ to $90^{\circ}$ were examined with the aim of developing an empirical calculation algorithm for the estimation of the joining forces and the torque capacity of I-KIF. Analogous to the shaft chamfer angle of external knurling, higher hub chamfer angle of I-KIF leads to lower joining forces, lower axially transmittable forces and lower maximal torque [10].

a)

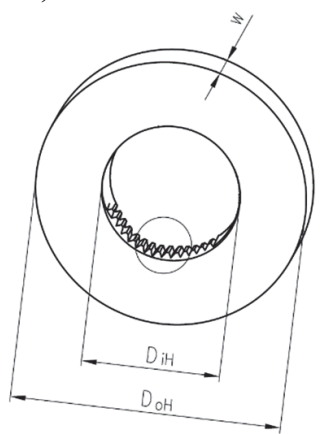

b)

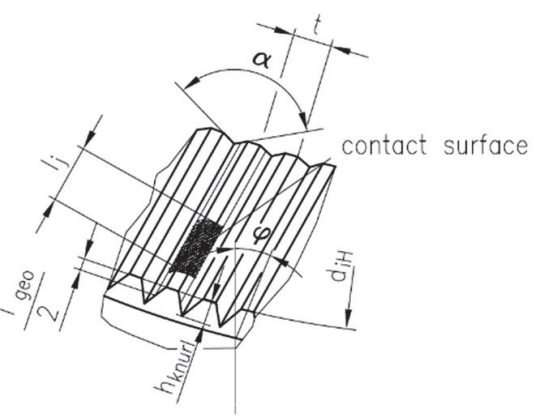

c)

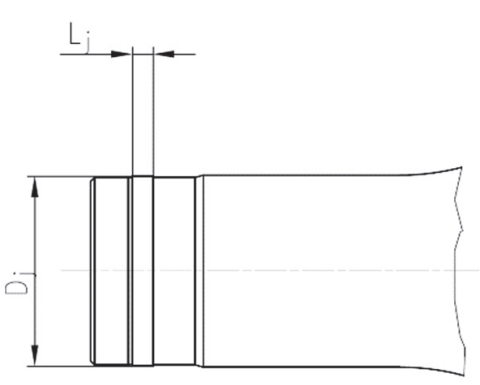

d)

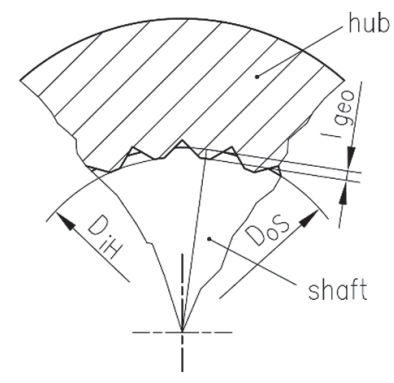

Figure 1: Geometry parameters of inner knurled KIF, a)-b) hub parameter, c) shaft parameter, d) assembled shaft-hub-specimen

After a rest period of 24 hours, the assembled specimen (Figure $2 \mathrm{~b}$ ) was mounted on a fatigue test bench and exposed to an alternating harmonic torsional load $(R=-1)$ powered by a hydraulic drive (Figure $2 \mathrm{a})$. In order to determine the torsional fatigue, the staircase method [15] with the logarithmic load gradation was used.

The maximum number of load changes was defined as $10^{7}$ cycles due to the late fatigue break point of contact-based specimens. A typical thin-walled specimen geometry cannot be implemented because of application related specimen. Therefore, the switch-off criterion during testing was the defined loss of torsional stiffness resulting in a turning angle of $2^{\circ}$. Afterwards, magnetic crack detection was performed with the aim of reviewing the failure mechanism. Only specimen without visible cracks (Figure 4c) were rated as a "run out".

a)

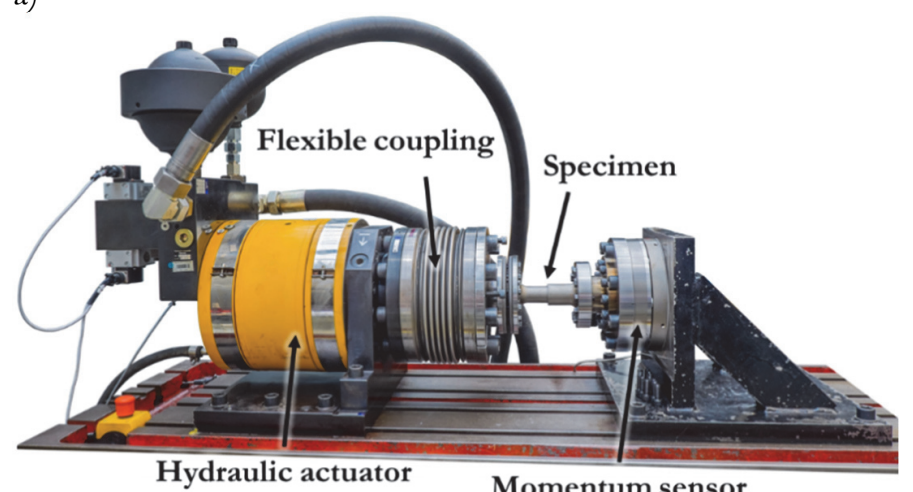

Momentum sensor b)

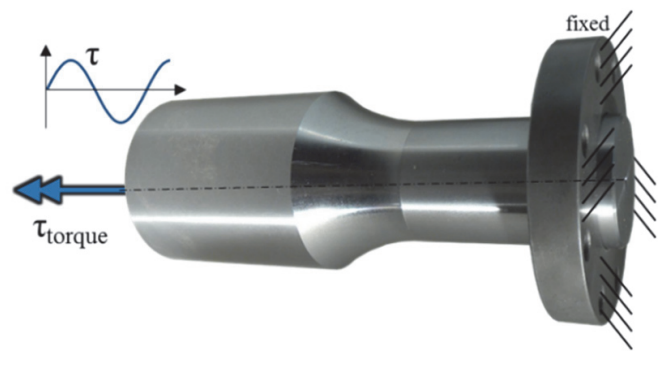

Figure 2: a) Test bench, b) Assembled specimen

The fatigue limit estimated according to the method of Hück [16] corresponds to $50 \%$ reliability.

$$
\tau_{a}=\tau_{a 0} \cdot d^{A / F}
$$

In this relation, $\tau_{a}$ is the fatigue limit, $\tau_{a 0}$ is the lowest level of the load staircase, and $d$ is the logarithmic interval depending on the standard deviation. Values $F$ and $A$ correspond to the sum of events at evaluated staircase levels as well as the multiplication with its ordinal numeral according to [15], [16]. 


\begin{tabular}{lll}
\hline Parameter & Symbol & Value \\
Hub diameter & $D_{i H}$ & $45 \mathrm{~mm}$ \\
Hub outer diameter & $D_{o H}$ & $95 \mathrm{~mm}$ \\
Joining length & $L j$ & $5 \mathrm{~mm}$ \\
Hub chamfer angle & $\varphi$ & $15^{\circ}, 90^{\circ}$ \\
Geometric interference & $I_{g e o}$ & $0.4 \mathrm{~mm}$ \\
Shaft diameter & $D_{o s}$ & $45.4 \mathrm{~mm}$ \\
\hline
\end{tabular}

Table 1: Geometry parameters of investigated inner knurled interference fit connection

\begin{tabular}{ccccc}
\hline & $\begin{array}{c}\text { Yield stress, } \\
\mathrm{MPa}\end{array}$ & $\begin{array}{c}\text { Tensile strength, } \\
\mathrm{MPa}\end{array}$ & $\begin{array}{c}\text { Strain to } \\
\text { rapture, \% }\end{array}$ & Hardness \\
\hline 16MnCr5 & $\begin{array}{c}426 \\
\text { (untreated) }\end{array}$ & $\begin{array}{c}632 \\
\text { (untreated) }\end{array}$ & $\begin{array}{c}26.9 \\
\text { (untreated) }\end{array}$ & $\begin{array}{c}785 \mathrm{HV} \\
\text { (case hardened) }\end{array}$ \\
$\mathrm{C} 45$ & $\begin{array}{c}387 \\
\text { (untreated) }\end{array}$ & $\begin{array}{c}664 \\
\text { (untreated) }\end{array}$ & $\begin{array}{c}25.7 \\
\text { (untreated) }\end{array}$ & $\begin{array}{c}233 \mathrm{HV} \\
\text { (untreated) }\end{array}$ \\
\hline
\end{tabular}

Table 2: Material properties.

Results

In comparison to the presented references, the maximum joining force (Figure $3 \mathrm{a}$ ) of connections joined by cutting $(\varphi=$ $\left.90^{\circ}\right)$ is also lower than the one of the formed connection $\left(\varphi=15^{\circ}\right)$. In contrast to the cutting method, where material is separated through chip formation, forming methods generate a higher friction force due to higher deflected radial forces. Characteristic curve features of the joining forces can be extracted as well as described in [14]. Compared to forming joining, for cutting I-KIF a higher slope can be determined at the beginning of the joining process (Figure 3a). The bend at approx. $1 \mathrm{~mm}$ of the stroke represents the pure cutting force. The following increase of the force can be linked to the increasing friction force due to the passive cutting force and growing contact area.

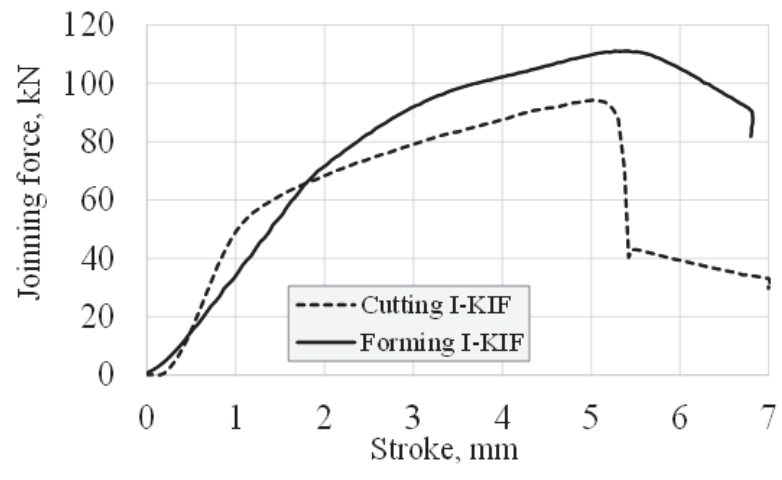

(a)

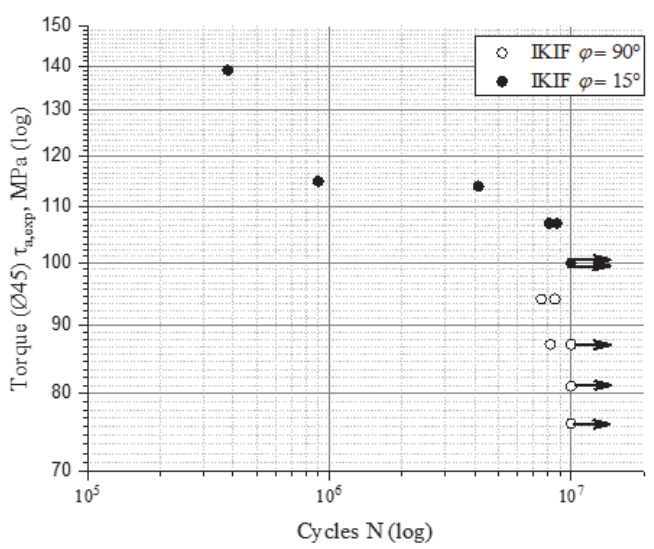

(b)

Figure 3: a) Joining forces of cutting and forming I-KIFs, b) Fatigue test results related to smooth surface of $\varnothing 45$

According to the Coulomb friction and the pressure-force-area-expression, the frictional force will grow with stroke. The last section of the joining curve $\left(\varphi=90^{\circ}\right)$ corresponds to the pure friction force at fully shaped joining length $L_{j}$. This force level also corresponds to the maximal axially transmittable force of the connection. 
At the end of the joining section at joining length $L_{j}$ the chip folds over (Figure 4 ) and remains a part of the shaft. The lower joining forces of cutting I-KIF indicate a lower local plastic strain at the groove root, which leads to lower strain hardening (Figure 3a). As reported by Lätzer [4], cutting joining of a KIF leads to a lower static torsional capacity. It is therefore assumed that both, the lower plastic strain and lower radial residual pressure, affect the cyclic properties of the cutting I$\mathrm{KIF}$.

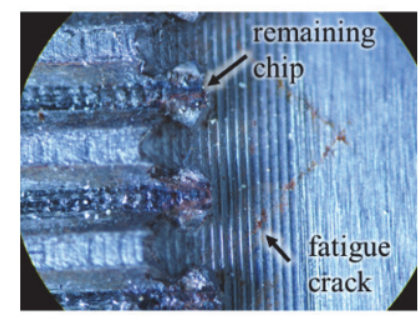

a)

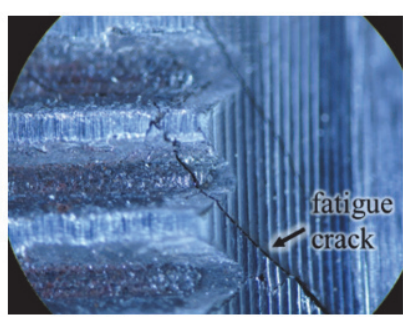

b)

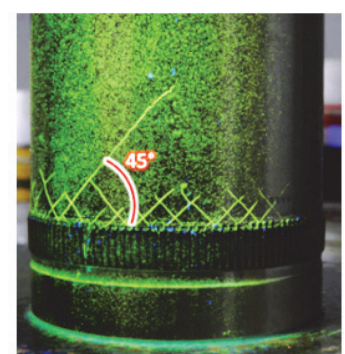

c)

Figure 4: Detected fatigue cracks at the shaft notch, material C45, $I_{g e o}=0.4 \mathrm{~mm}$, a) $\varphi=90^{\circ}$, b) $\varphi=15^{\circ}$, c) Global cracks.

Figure $3 \mathrm{~b}$ compares the results from fatigue testing, where the stress values are related to the smooth shaft surface of $\varnothing 45 \mathrm{~mm}$. The arrow points represent a run-out specimen related to $10^{7}$ cycles. Below this cycle limit, the depicted points correspond to a failure in the low-cycle fatigue region. The results of the magnetic crack detection show a typical crack propagation of $45^{\circ}$ for the applied torsional load (Figure 4c).

An approximately $14 \%$ higher fatigue limit of the strain-hardened test samples $\left(\varphi=15^{\circ}\right)$ is observed in comparison to the broaching type $\left(\varphi=90^{\circ}\right)$. This is similar to the static torque transmissibility of the I-KIF.

Referring to the fatigue limit of the smooth shaft net area, the estimated high-cycle limits result in a fatigue notch factor of 1.7 for the cutting I-KIF, compared to 1.4 for a formed connection according to the German standard for load capacity calculation of shafts and axles DIN 743 [14].

Although a positive effect of plastic pre-strain on fatigue strength was observed in basic research [11], [12] the grain structure evaluation in Figure 5 shows similar grain refinement on the surface near the area of both, cutting and forming joining process. Therefore, the increase of fatigue limit rather has to be linked to the higher groove pressure of formed knurling. In [14], higher residual pressure stresses were estimated for the presented connection. Additionally in Figure 5b, the grain structure underneath the surface of the formed shaft knurling shows a stretched pattern, which can also be associated with higher radial pressure.

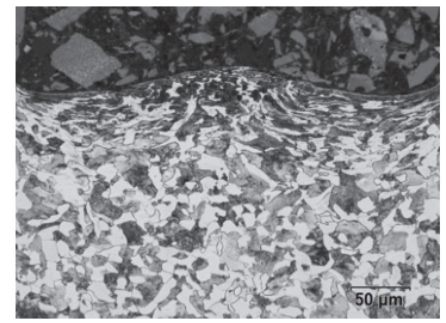

a)

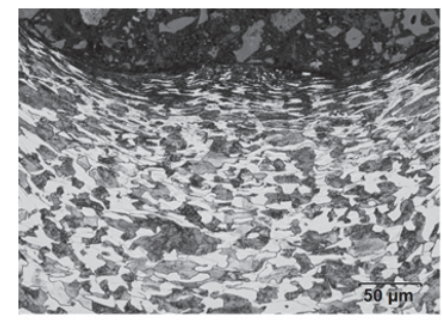

b)

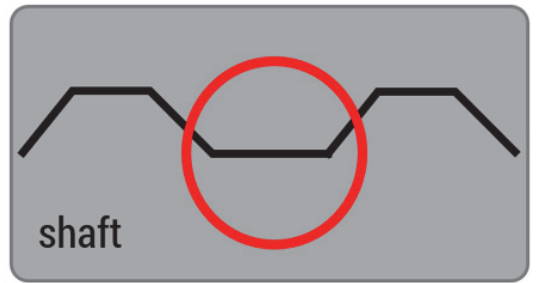

c)

Figure 5: Grain structure of a) the cut shaft knurling $\left(\varphi=90^{\circ}\right)$, b) the formed shaft knurling $\left(\varphi=15^{\circ}\right)$. c) Location of grain evaluation

\section{CONCLUSION}

he present work has introduced the experimental investigations of the inversed knurled interference fit, which is a novel connection type for transmitting torque with high power density. By moving away from the pairing conditions of the well-known knurled interference fit (knurled and harder shaft) to the connection of the inner-knurled hardened hub with the softer smooth shaft, beneficial residual compression stresses are achieved in the shaft. The presented results also show the influence of the hub chamfer angle on the high-cycle fatigue of the connection. Concerning forming joining, a 14\% higher endurance limit was achieved by using a hub chamfer angle of $\varphi=15^{\circ}$ due to higher radial residual 
stresses achieved during the joining process. As a result, not only a higher fatigue limit is achieved but also a higher capacity of axial forces in forming I-KIF is reached.

Despite the limitations of the cutting I-KIF, some applications with thin-walled hubs require a small radial expansion, which a forming I-KIF cannot perform. In addition, the designing of a hub chamfer angle above $\varphi=15^{\circ}$ can lead to less radial stresses due to a better cutting edge. Appropriate geometry parameters can therefore be chosen depending on the requirements of the component connection.

\section{ACKNOWLEDGEMENT}

7 he authors would like to thank the DFG (German Research Foundation), which made the research project no. 249500173 possible.

\section{REFERENCES}

[1] Hildebrand, S. (1980). Feinmechanische Elemente. Berlin: VEB Verlag Technik.

[2] Thomas, K. (1969). Die Presspassung mit unterbrochener Fuge“, PhD-Thesis, Technische Universität Hannover.

[3] Bader, M. (2009). Das Übertragungsverhalten von Pressverbänden und die daraus abgeleitete Optimierung einer formschlüssigen Welle-Nabe-Verbindung“, PhD-Thesis, Technische Universität Graz, Graz.

[4] Lätzer, M. (2016). Joining and transmission behaviour of torsional stressed steel-aluminum knurled interference fits“, PhD-Thesis, Technische Universität Chemnitz, Chemnitz, Germany.

[5] Mänz, T., Auslegung von Pressverbindungen mit gerändelter Welle, PhD-Thesis, Technische Universität Clausthal, Clausthal.

[6] Suchý, L., Leidich, E., Gerstmann, T. and Awiszus, B. (2018). Influence of Hub Parameters on Joining Forces and Torque Transmission Output of Plastically-Joined Shaft-Hub-Connections with a Knurled Contact Surface, Machines, $6(2)$.

[7] Kleditzsch, S., Awiszus, B., Leidich, E. and Lätzer, M. (2015). Numerical and Analytical Investigation of SteelAluminum Knurled Interference Fits: Joining Process and Load Characteristics, Journal of Materials Processing Technology, 219, pp. 286-294.

[8] Rennert, R., Kullig, E., Vormwald, M. and Siegele, D. (2012). Analytical Strength Assessment 6.th Edition, 6. Aufl. Forschungskuratorium Maschinenbau (FKM), 2012.

[9] Coban, H., Silva, K. M. D., and Harrison, D. K. (2009). Mill-knurling as an alternative to laser welding for automotive drivetrain assembly, CIRP Annals, 58(1), pp. 41-44.

[10] Suchý, L., Leidich, E., Hasse, A., Gerstmann, T. and Awiszus, B. (2018). Inner knurled interference fit as a further development of the conventional knurled interference fit, in VDI-Berichte 2337, Stuttgart.

[11] Ruffing C. et alii (2015). Fatigue Behavior of Ultrafine-Grained Medium Carbon Steel with Different Carbide Morphologies Processed by High Pressure Torsion, Metals, 5(2), pp. 891-909.

[12] Kang, M., Aono, Y. and Noguchi, H. (2007). Effect of pre-strain on and prediction of fatigue limit in carbon steel“", International Journal of Fatigue, 29(9), pp. 1855-1862.

[13] ISO 6892-1, Metallic Materials_-Tensile Testing_-Part 1: Method of Test at Room Temperature,. Geneva: International Organization for Standardization, (2017).

[14] DIN 743, Calculation of load capacity of shafts and axles. DIN Deutsches Institut für Normung e. V., (2012).

[15] DIN 50100, Load controlled fatigue testing - Execution and evaluation of cyclic tests at constant load amplitudes on metallic specimens and components. (2016).

[16] Hück, M. (1983). An improved procedure for the evaluation of staircase step tests (German: Ein verbessertes Verfahren fur die Auswertung von Treppenstufenversuchen)“, Zeitschrift Werkstofftechnik, 14, pp. 406-417. 